Portland State University

PDXScholar

Psychology Faculty Publications and

Presentations

Psychology

$10-4-2019$

\title{
Mixed Signals: The Unintended Effects of Diversity Initiatives
}

Tessa L. Dover

Portland State University, tessa.dover@pdx.edu

Cheryl R. Kaiser

University of Washington

Brenda Major

University of California, Santa Barbara

Follow this and additional works at: https://pdxscholar.library.pdx.edu/psy_fac

Part of the Psychology Commons

Let us know how access to this document benefits you.

Citation Details

Published as: Dover, T. L., Kaiser, C. R., \& Major, B. (2019). Mixed signals: The unintended effects of diversity initiatives. Social Issues and Policy Review.

This Post-Print is brought to you for free and open access. It has been accepted for inclusion in Psychology Faculty Publications and Presentations by an authorized administrator of PDXScholar. Please contact us if we can make this document more accessible: pdxscholar@pdx.edu. 
Mixed Signals: The Unintended Effects of Diversity Initiatives

Tessa L. Dover

Portland State University

Cheryl R. Kaiser

University of Washington

Brenda Major

University of California, Santa Barbara

Author Note

Tessa L. Dover, Department of Psychology, Portland State University; Cheryl R. Kaiser, Department of Psychology, University of Washington; Brenda Major, Department of Psychological and Brain Sciences, University of California, Santa Barbara.

Correspondence concerning this article should be addressed to Tessa L. Dover, Department of Psychology, Portland State University, 1721 SW Broadway, Portland, OR 972070751. Email: tdover@pdx.edu 


\begin{abstract}
Organizational diversity initiatives — programs and policies intended to increase the fairness of organizations and promote the inclusion, hiring, retention, and promotion of underrepresented groups - are ubiquitous. Despite the widespread implementation of diversity initiatives, several empirical investigations point to challenges associated with these initiatives. We suggest that one of the challenges hindering the effectiveness of diversity management involves the unintended signals that these initiatives send. Specifically, we review social psychological evidence that the mere presence of diversity initiatives can have unintended consequences through the communication of (1) fairness signals, (2) inclusion signals, and (3) competence signals. The presence of organizational diversity initiatives may lead to a presumption of fairness for underrepresented groups, making discrimination harder to identify and litigate. Conversely, these initiatives may lead to a presumption of unfairness for members of overrepresented groups, increasing the likelihood that traditionally-advantaged groups will perceive themselves as victims of discrimination. The presence of diversity initiatives may increase the attractiveness of organizations to underrepresented groups who anticipate inclusion, but increase felt exclusion and threat among overrepresented groups. Finally, the presence of diversity initiatives may signal that underrepresented groups need help to succeed and are thus less competent than their advantaged counterparts. Researchers and practitioners should note the potential unintended signaling consequences of diversity initiatives, and build-in accountability and social psychological knowledge when designing policies aimed at creating inclusive, diverse, and fair workplaces.
\end{abstract}




\section{Mixed Signals: The Unintended Effects of Diversity Initiatives}

Although laws prohibiting employment discrimination on the basis of sex, race, color, national origin, disability, and religion, have been in effect for decades in many nations, employment discrimination persists. Field experiments in Europe, North America, Asia, South America, and Australia demonstrate that identically qualified job applicants experience differential callbacks and job offers as a function of their demographic characteristics (Baert, 2018). A meta-analysis of U.S. field experiments finds that racial discrimination - especially for African Americans_-has not declined since 1989 (Quillian, Pager, Hexel, \& Midtbøen, 2017).

The continuing prevalence of employment discrimination raises questions about why we still have so much further to go in realizing the protections offered by anti-discrimination law. Several reasons might help explain this. Discriminatory behavior can persist even among those with sincerely egalitarian ideals (Dovidio \& Gaertner, 2004), making discrimination hard to target. Stigma is also notoriously flexible and insidious (Link \& Phelan, 2001), which may allow discrimination and exclusion to persist in ways that are hard to identify and less actionable in courts (McGuire, 2002; Welle \& Heilman, 2007). We suspect that the disconnect between antidiscrimination law and the reality of discrimination in contemporary workplaces might also stem from ineffective or unintentionally counterproductive organizational policies.

Although organizations are told that they cannot discriminate, they are not actually given evidence-based strategies to prevent discrimination and create equal opportunities. They are left to their own devices to solve the problem of employment discrimination (Dobbin \& Kalev, 2017). In medicine, practitioners realized long ago that evidence-based practices are critical to sound intervention. Yet, in organizations we seem content to try anything that might reasonably reduce discrimination, irrespective of evidence (Edelman, Krieger, Eliason, Albiston, \& Mellema, 2011). Thus, civil rights compliance is often left to well intentioned, yet non-evidence 
based, practitioners who offer diversity initiatives without exploring whether they are successful or whether they may have unintended consequences.

In this paper, we focus on these organizational diversity initiatives and their role in facilitating or undermining the goal of creating fair workplaces. In particular, we use insights from the social psychological literature to examine the signaling function of organizational diversity initiatives - how their presence affects perceptions of organizations and those who work within them. We argue that the signals sent by diversity initiatives can unintentionally hinder the very goals these initiatives aim to achieve. In particular, the presence of organizational diversity initiatives can make it more difficult to recognize and adjudicate discrimination targeted at disadvantaged groups, increase sensitivity to discrimination against advantaged groups, cause threat and perceptions of victimhood among advantaged groups, and lead to questioned competence and attributional ambiguity for members of disadvantaged groups.

Our review is presented in three sections. First, we provide some background on how organizations have approached diversity management, and evidence challenging the efficacy of the most common diversity initiatives. In the second section, we discuss three major signals sent by organizational diversity initiatives that may undermine their goals: (1) fairness signals, (2) inclusion signals, and (3) competence signals. In the final section, we present social and policy implications, discussing strategies practitioners and policymakers might consider when trying to create fair and inclusive workplaces.

\section{Approaches to Organizational Diversity Management}

Though the primary goal of most diversity initiatives is to create more fair, diverse, and inclusive workplaces, organizational attempts at managing diversity vary widely. The most common forms include diversity training, pro-diversity marketing on websites and recruitment materials, traditional affirmative action policies, targeted recruitment efforts, diversity 
committees and specialized diversity management personnel, mentorship programs, and affinity groups (see Berrey, 2015; Kalev, Dobbin, \& Kelly, 2006; Leslie, 2018). Several recent highprofile examples can illustrate how global companies approach diversity management: In 2018, Nike adopted mandatory unconscious bias training for managers, created new diversity executive positions, and instituted a hiring and compensation monitoring system in response to harassment and pay discrimination claims (Chen, 2018). In 2018, Starbucks announced a day of diversity training in all corporate and retail locations in response to a racist incident in one of their stores (Scheiber \& Abrams, 2018). In 2015, both Google and Facebook announced a multi-million dollar investments in diversity, new hiring targets, and organizational culture reforms after lackluster diversity numbers were released (Feloni, 2016; Guynn, 2015). Though not all diversity initiatives are adopted in response to headline-generating diversity problems, these examples provide an idea of the programs and policies commonly instituted to address diversity in the workplace. They also illustrate the extent to which organizations and the public believe that diversity is a pressing issue that demands attention from organizational leaders.

According to a 2017 estimate, Fortune 500 companies jointly spend upwards of $\$ 16$ billion on diversity management each year (Staley, 2017). It is clear that the world's largest companies are taking diversity seriously. However, the decentralized approach in which each organization implements a unique diversity management strategy creates a challenge for policy evaluators attempting to assess the actual effects diversity initiatives have on important outcomes. Evaluating the effects of diversity management is also challenging because organizational diversity initiatives are often designed with multiple goals in mind.

\section{Why Adopt Diversity Initiatives?}


Organizations adopt diversity initiatives for several reasons. These reasons, summarized below, include creating fairer workplaces, creating more efficient and effective workplaces, and communicating an organization's values.

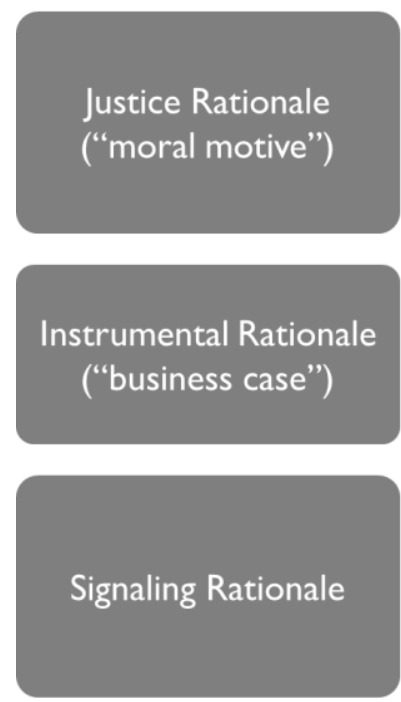

Overall Goal: Create Fairer Workplaces

- Reduce workplace discrimination against protected classes

- Facilitate reporting \& remediation of discriminatory actions

- Prevent retaliation against discrimination claimants

- Comply with anti-discrimination law Overall Goal: Create More Efficient \& Effective Workplaces

- Capitalize on diverse perspectives \& cultural knowledge

- Remove inefficiencies (interpersonal conflict, tension, loss of talent) caused by prejudice and discrimination

Overall Goal: Communicate Pro-Diversity Values to Stakeholders

- Attract candidates from underrepresented groups

- Encourage pro-diversity values \& behavior among employees

- Demonstrate commitment to justice to investors, employees, job candidates, and general public

The justice rationale (also sometimes called the moral motive) stems from a desire to establish equal access, fair treatment, and workplace environments that are free from discrimination and harassment. This motive can be seen as the fundamental or "first generation" rationale guiding diversity management programs, as many of the first programs and policies we would now call diversity initiatives were designed primarily as anti-discrimination efforts.

According to the justice rationale, organizations should adopt diversity initiatives in order to create just - and legally compliant — workplaces. This involves creating workplaces in which discrimination against protected classes is eliminated, in which discriminatory treatment is addressed seriously by management, in which discrimination can be reported without fear of retaliation, and in which members of traditionally excluded groups have a right to work free from harassment and discrimination.

The instrumental rationale (also sometimes called the "business case" for diversity; Cox \& Blake, 1991) is based on the belief that a diverse and discrimination-free workplace makes an 
organization more competitive and profitable. This motive to enhance firm performance via diversity and inclusion can be seen as a "second generation" rationale, and reflects a fundamental shift from the justice rationale. Whereas the justice rational conceptualizes organizational diversity initiatives as a responsibility, the instrumental rationale conceptualizes them as an opportunity. In this way, the adoption of diversity initiatives aligns with an organization's financial imperatives of efficiency and efficacy. According to this rationale, diversity initiatives help give companies a competitive edge because they draw on a breadth of perspectives and experiences. This rationale may be particularly important in an increasingly globalized marketplace where cultural knowledge and diverse backgrounds are required for maintaining competitiveness. Further, an inclusive, prejudice-free workplace can prevent some of the inefficiencies associated with discrimination-loss of talent, tension between diverse employees, and low institutional commitment.

The signaling rationale refers to efforts to communicate an organization's values to current employees, potential employees, or the general public. In contrast to justice and instrumental rationales, the signaling rationale has received much less attention in the literature. Nevertheless, signaling represents both an important motive that organizations consider when deciding whether/how to adopt diversity initiatives, as well as an important predictor of how we think about diversity initiatives and organizations that adopt them. Signaling motives can be conceptualized as a "third generation" rationale in which organizations seek to clarify an organization's values, communicate an organization's values, or convince interested parties that it has certain values. Though some evidence suggests that organizations adopt diversity initiatives strictly for signaling purposes (i.e., 'colorful window dressing;' Marques, 2010), the signaling motive is likely layered on top of justice or instrumental rationales. Organizations with 
this motive, in other words, may believe that sending particular signals will indirectly result in a more just or productive workplace.

For example, a webpage that discusses an organization's commitment to diversity may function to signal the organization's values to current employees, thus providing top-down instruction on how to treat colleagues. The same webpage could signal to potential employees that the workplace is inclusive and fair to members of different groups, thus allowing the organization to recruit a more diverse workforce. It may also signal to legal actors, investors, customers, or other interested parties that the organization is committed to justice. Signaling has become more important as the public has called for evidence that corporations are addressing systemic inequality (Johansson, 2017), as brands have sought recognition as being "sociallyconscious" (see King \& McDonnell, 2015), as business publications including Forbes and Fortune have begun recognizing pro-diversity efforts, and as the internet has allowed for more direct interactions between organizations and the public.

Signaling motives may be particularly important when organizations face threats to their public image. In the examples from Nike, Starbucks, Google, and Facebook, for instance, the organizations were likely motivated by a desire to be more just (the justice rationale) and a concern that discrimination and harassment were creating less effective and efficient workplaces (the instrumental rationale). The signaling rationale also likely played an important role in their decisions to implement new diversity initiatives. In the case of Starbucks, for example, several activist groups called for the company to address their racial bias problem; employees may have been concerned with working for an organization that did not take racial sensitivity seriously; shareholders, investors, and management were likely concerned about public relations and the \#BoycottStarbucks movement; and brand loyalists with egalitarian ideologies may have been eager to return to the stores without guilt. In short, Starbucks likely wanted to signal to all these 
interested parties that they were taking the incident seriously and were doing something to address their racial diversity issues. Many of these concerns could be alleviated by initiatives that signaled pro-diversity values, even in the absence of evidence that the initiatives created any meaningful change.

\section{Do Diversity Initiatives Create More Fair and Inclusive Organizations?}

Whatever the rationale for adopting diversity initiatives, one could argue that they are an important and valuable social good because they create fairer workplaces and support the careers of traditionally underrepresented groups. Several investigations indicate that workplaces perceived as fair and diversity-supportive are beneficial for worker morale, productivity, and commitment (Avery, McKay, Wilson, \& Tonidandel, 2007; McKay, Avery, Tonidandel, Morris, Hernandez, \& Hebl, 2007; Hicks-Clarke \& Iles, 2000; Plaut, Thomas, \& Goren, 2009). Further, some work suggests that diversity initiatives play a role in fostering these positive and fair environments (King, Dawson, Kravitz, \& Gulick, 2012; Smith, Turner, Osei-Kofi, \& Richards, 2004; Waight \& Madera, 2011). Because of the benefits of fair and inclusive workplaces, many have called for the implementation of diversity training and other organizational diversity initiatives (Bell, Connerly, \& Cocchiara, 2009; Bell \& Kravitz, 2008; Pendry, Driscoll, \& Field, 2007). However, little in the way of rigorous empirical evidence supports the conclusion that implementing a diversity initiative leads to less prejudice, less discrimination, or more representation of traditionally-excluded groups. In other words, whereas diversity-supportive workplaces are associated with positive benefits, there is little evidence that the adoption of diversity initiatives is a causal factor leading to these positive benefits. We review some of this evidence below, and then suggest that unintended signaling consequences may be partially responsible for these mixed effects. 
Research focused on the efficacy of diversity training interventions has focused primarily on the impact of diversity training on individual participants rather than organizational outcomes. Several systematic reviews and a meta-analysis, based primarily on data from the U.S. (Bezrukova, Jehn, \& Spell, 2012; Bezrukova, Spell, Perry, \& Jehn, 2016; Kulik \& Roberson, 2008a; 2008b), conclude that diversity training can have positive effects on immediate attitudes toward diversity and knowledge about other cultures, but has at best mixed effects on prejudice toward specific groups. In addition, many of the positive effects of diversity training on attitudes toward diversity decline with time (Bezrukova et al., 2016). Importantly, assessments of diversity training are also quite susceptible to demand characteristics in which participants adjust their responses in an attempt to behave as they believe the researchers want them to. This makes it possible that positive outcomes of diversity training might not translate to changes in sincere beliefs, changes that last once the participants return to the organizational setting, or changes in behavior toward members of disadvantaged groups (see Roberson, Kulik, \& Tan, 2012).

Research assessing changes in implicit bias may alleviate some of these concerns, as measures of implicit bias are less susceptible to demand characteristics and are less under individual control (Fazio \& Olson, 2003; Hofmann, Gawronski, Gschwender, Le, \& Schmitt, 2005). Implicit bias training, however, also has modest and mixed effects, and almost universally fails to lead to behavioral or long-lasting changes (Forscher, Lai, Axt, Ebersole, Herman, Devine, \& Nosek, 2016; Lai et al., 2014; 2016). Other work has also revealed some unintended consequences of implicit bias training, including increased prejudice and defensiveness after learning about one's implicit bias (Howell \& Ratcliff, 2017; Howell, Redford, Pogge, \& Ratliff, 2017; Hussey \& De Houwer, 2018). These lackluster findings suggest that implicit bias training will be unlikely to reduce prejudice and discrimination in the workplace. Indeed, even the 
developer of the Implicit Association Test, a central component in implicit bias training, warns that implicit bias training is unlikely to reduce workplace discrimination (Herzog, 2018).

Almost no published literature assesses training outcomes within actual workplaces or tracks how changes in attitudes correspond to changes in behavior (for an important exception, see Carnes et al., 2015; Devine et al., 2012; 2017, which we discuss further below). The few investigations that do provide mixed effects. For example, Naff and Kellough (2003) found null or negative associations between the presence of several types of diversity initiatives and the representation of women and minorities in U.S. federal agencies. Similar null or negative effects were found for retention and promotion of women and minorities in U.S. federal agencies (Kellogh \& Naff, 2004). More recently, an international field experiment assessed the effects of diversity training on both attitudes and behavior by enrolling volunteers at a multinational company in a bias training program and assessing behavior surreptitiously at a later date (Chang, Milkman, Gromet, Rebele, Massey, Duckworth, \& Grant, 2019). Diversity training focused on gender or racial bias (vs. a control training) led to modest decreases in bias among nonAmericans and those with low initial levels of bias, but the intervention did not affect bias among Americans or among those with high levels of initial bias. Behavioral outcomes were also mixed: after the bias (vs. control) training, women and ethnic minority participants were more likely to nominate fellow women or minorities to be recognized for their excellence, and women were more likely to sign-up to seek mentorship. But men and whites did not show these effects, indicating that diversity training might be least effective among those most in need of such training (see also Noon, 2018). All together, this work suggests that diversity training may have modest effects on attitudes and knowledge, but may not translate to behavior or better outcomes within actual organizations. 
One of the most authoritative studies assessing the effects of implementing a diversity initiative in organizations tracked 708 U.S. organizations between 1971 and 2002 (Kalev et al., 2006). This analysis used federal employment records and surveys of organizational representatives to determine what changes in managerial demographics occurred after organizations adopted various diversity initiatives. This allowed the authors to not only assess whether the adoption of a diversity initiative was associated with subsequent changes in the demographic makeup of organizational leaders, but also whether certain types of initiatives were more likely to result in changes. Analyses revealed that on the whole, adopting a diversity initiative was associated with some improvements in managerial representation of white women. However, effects were small and the authors concluded that alone, even the most effective forms of diversity management (establishment of a diversity committee; appointing a full-time diversity staff member) 'will not soon change the look of management" (p. 612). Moreover, certain types of initiatives (diversity training, diversity evaluations, and networking programs) were associated with decreased representation of some minority groups, including black women and black men. Follow-up research has found that diversity training programs (particularly mandatory diversity training programs) and other attempts at preventing managers from discriminating are particularly ineffective at increasing the representation of white women and racial/ethnic minorities in organizational management (Dobbin, Schrage, \& Kalev, 2015). This work functioned as a wake-up call for scholars and practitioners, because it provided straightforward evidence that many of the most common forms of diversity initiatives, particularly diversity training, often fail at their most basic goal—creating more diverse workforces - and that these initiatives might also work in the opposite direction as intended..

In summary, the empirical data point to some promising areas for intervention, but do not support the conclusion that the adoption of diversity initiatives as currently practiced- 
particularly diversity training interventions-will successfully create fair and diversitysupportive environments.

There are many reasons for the lack of consistent positive effects of diversity initiatives and the continued prevalence of employment discrimination despite huge investments in diversity management. We suggest that one important reason that diversity initiatives often fall short of creating fairer, more inclusive, and more diverse workplaces involves the unintended and under-examined signaling consequences of diversity initiatives. In particular, we argue that the implementation of diversity initiatives may ironically work against the stated goals of these initiatives by (1) leading people to assume an organization is less discriminatory against minority groups and more discriminatory against majority groups, (2) leading to perceptions of exclusion among members of advantaged groups that can prompt backlash, and (3) leading to biased assumptions about the competency of members of disadvantaged groups. These signaling consequences must be acknowledged and taken seriously by policymakers and practitioners, particularly in light of evidence challenging the efficacy of many diversity initiatives.

\section{Signaling Consequences of Organizational Diversity Initiatives}

Regardless of whether a diversity initiative succeeds in reducing discrimination or creating a more inclusive environment, individuals will interpret diversity initiatives as signals of what an organization is like. These signals sometimes match the intentions of the organizational leaders implementing them — for example, they may lead individuals to believe that members of underrepresented groups are valued in the organization. However, these signals can also be disconnected from the intentions of the organizational leaders-for example, they may lead individuals to believe that members of overrepresented groups are not valued in the organization. Importantly, even when intended, these signals may have additional unintended consequences that organizations may not fully appreciate. Here, we focus on three signals that diversity 
initiatives send that may have unintended negative consequences: (1) fairness signals, (2) inclusion signals, and (3) competence signals. The work we review below, unless otherwise mentioned, is derived primarily from North American samples.

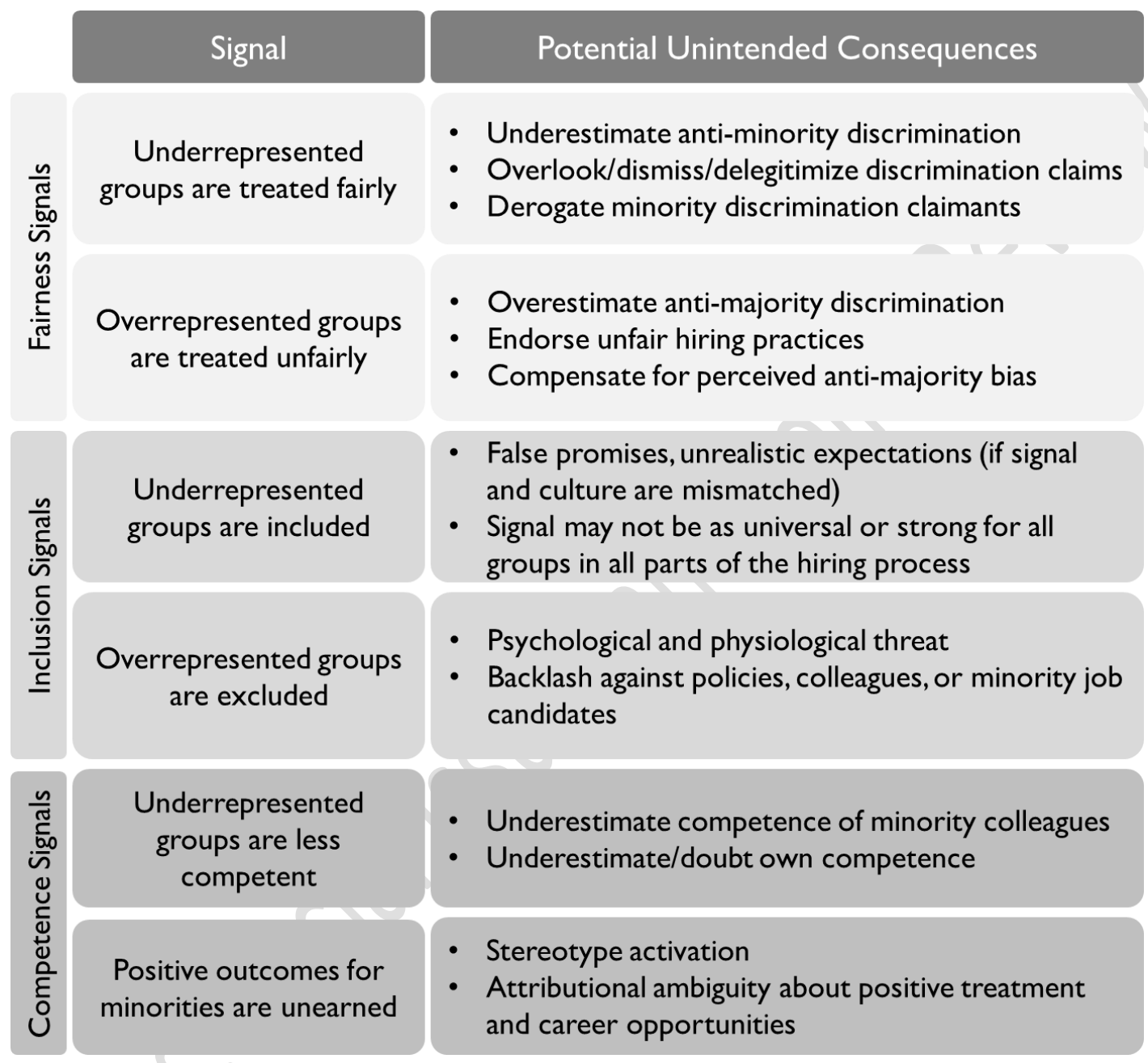

\section{Fairness Signals}

Most diversity initiatives intend to communicate that members of underrepresented groups will be treated fairly and hence will be able to succeed within the organization. Research indicates that organizations with diversity initiatives are perceived as more procedurally fair for traditionally underrepresented groups than comparable organizations without diversity initiatives (Brady, Kaiser, Major, \& Kirby, 2015; Chaney, Sanchez, \& Remedios, 2016; Dover, Major, \& Kaiser, 2016; Kaiser, Major, Jurcevic, Dover, Brady, \& Shapiro, 2013). From the perspective of 
an organizational leader, this fairness signal could be considered an important and positive outcome. Workers who feel that their environments are procedurally fair are more content, have higher job satisfaction, and higher organizational commitment (McFarlin \& Sweeney, 1992; Moorman, Niehoff, \& Organ, 1993). However, a growing body of research documents that this intended fairness signal can also have unintended consequences.

Decreased sensitivity to unfairness. One unintended consequence is decreased sensitivity to unfair hiring practices that disadvantage women or minorities. For example, whites perceive organizations with diversity initiatives as more fair for women and minorities even when presented with evidence that the company has engaged in unfair hiring practices (Kaiser et al., 2013; Dover, Major, \& Kaiser, 2014). The mere presence of a diversity initiative also makes whites and men less likely to identify hiring disparities as unfair (Kaiser et al., 2013, Study 2), and can lead to greater acceptance of hiring practices that tend to perpetuate injustice. For example, unstructured interviews tend to disadvantage racial minorities and women, whereas standardized interviews reduce hiring disparities (Huffcutt \& Roth, 1998; Levashina, Hartwell, Morgeson, \& Campion, 2014). Nonetheless, the presence (vs. absence) of diversity initiatives led participants to be more likely to think that unstructured interviews were fair for minorities and recommend adopting unstructured (vs. structured) interview procedures (Kirby, Kaiser, \& Major, 2015). In short, the mere presence of a diversity initiative signals to whites that an organization treats minority employees and women fairly, even when there is evidence to the contrary.

De-legitimization of discrimination claims made by underrepresented groups. A related unintended consequence of the signal that underrepresented groups in pro-diversity organizations are treated fairly is decreased support for discrimination claims made by underrepresented groups. For example, members of advantaged groups are less supportive of discrimination claims and lawsuits brought by minorities and women at companies with (vs. without) diversity 
initiatives, and see an organization with (vs. without) diversity initiatives as less responsible for alleged discrimination (Brady et al., 2015; Dover et al., 2014). The presence of diversity initiatives also affects derogation of minority claimants seeking legal redress for discrimination. For example, whites who read about a discrimination claim made by a Latino man perceived the organization as less discriminatory and derogated the claimant more when the company mentioned (vs. did not mention) its diversity initiatives (Dover et al., 2014). Similarly, men were more likely to derogate a woman claiming gender discrimination when the organization had (vs. did not have) pro-diversity initiatives (Brady et al., 2015). In short, rather than sensitizing members of advantaged groups to discrimination against women and minorities and protecting minority discrimination claimants, diversity initiatives that signal procedural fairness for underrepresented groups may lead individuals to overlook or deny discrimination.

The bulk of work examining the signaling effects of diversity initiatives on sensitivity to discrimination and support of discrimination claims made by women and minorities has focused on participants from advantaged groups (e.g., whites, men). The few studies that have examined their effects among members of traditionally underrepresented groups suggest that fairness signal may be more nuanced among these groups. Some studies suggest that effects are moderated by endorsement of traditional and meritocratic values. Among women assessing the merits of a discrimination claim brought by a woman against a company that had engaged in unfair hiring practices, the presence (vs. absence) of diversity initiatives led to greater perceived fairness and reduced perceptions of discrimination only among women high in benevolent sexism (a belief that women adhering to traditional gender roles should be protected and valued; Glick \& Fiske, 1996). Among women who did not endorse benevolent sexist attitudes, the presence of a diversity initiative did not influence perceptions of fairness or discrimination (Brady et al., 2015). Another study showed that the presence (vs. absence) of a diversity initiative led Latinx 
participants to perceive less discrimination against a Latinx employee who brought a discrimination lawsuit and to derogate the claimant more only when they believed the social system is fair (Dover et al., 2014).

Increased sensitivity to discrimination against advantaged groups. Diversity initiatives also send signals about how members of traditionally advantaged groups will be treated. To whites, diversity initiatives appear to signal unfair treatment of whites and lead to increased sensitivity to discrimination against whites. Across one series of experiments (Dover et al., 2016), white participants who learned about two different companies — one with diversity initiatives and one without diversity initiatives - perceived the former as less procedurally fair for whites than for minorities. This series of experiments also found that white male job applicants anticipated greater likelihood of discrimination against whites than against minorities at a company that valued (vs. did not mention) diversity. More recently, a set of experiments exposed white participants to a scenario in which a black employee received a promotion that a white employee also wanted (Kaiser, Dover, Small, Xia, Brady, \& Major, 2019). Across ten studies, white participants perceived that the organization was less procedurally fair for whites than for minorities when they had previously learned (vs. did not learn) that the organization had diversity initiatives. In addition, participants were more likely to believe that the organization discriminated against whites in the presence (vs. absence) of a diversity initiative. Black participants did not similarly show increased sensitivity to anti-white discrimination in the presence (vs. absence) of diversity initiatives (Kaiser et al., 2019). This suggests that the mere presence of organizational diversity initiatives can lead advantaged groups to believe an organization favors minorities over whites, and can lead them to interpret the career advancement of minority employees as a function of "reverse discrimination." 
Fairness signals: Implications. From the perspective of an organization, the signal that members of disadvantaged groups are treated fairly and face little discrimination may be beneficial from a financial, legal, and public-image perspective. Edelman, Fuller, and Mara-Drita (2011), for example, find that organizations defending themselves in discrimination lawsuits are advantaged when they can point to a diversity policy, even if they cannot point to evidence that the diversity policy makes discrimination less likely. This approach in litigation has been coined a "diversity defense" (Kaiser \& Quintanilla, 2014). The 2011 U.S. Supreme Court decision to deny a class-action sex discrimination lawsuit against Wal-Mart was partially based on this defense. The majority opinion argued, "Wal-Mart's announced policy forbids sex discrimination... left to their own devices most managers in any corporation - and surely most managers in a corporation that forbids sex discrimination-would select sex-neutral, performance-based criteria for hiring and promotion" (Wal-Mart Stores, Inc. vs. Dukes, 2011). Clearly, the fairness signal of diversity initiatives can work on the behalf of organizations accused of discrimination. For organizations with a justice rationale for implementing diversity initiatives, however, this fairness signal likely works against their goals. If discrimination against disadvantaged groups goes unnoticed or under-acknowledged, it will be more challenging to identify, safely report, and remediate.

Organizations might also be concerned that the fairness signals sent by diversity initiatives might lead to a greater number of discrimination claims from whites and men. Many "reverse discrimination" lawsuits brought forth by traditionally advantaged groups have challenged the legality of affirmative action policies in educational contexts (Fisher vs. University of Texas, 2013; 2016; Regents of University of California vs. Bakke, 1978), and discrimination lawsuits filed by men, whites, and heterosexuals are increasing internationally (Bi, 2016; Evans, 2004; e.g., M Furlong v. The Chief Constable of Cheshire Police, 2019; Smith 
v. Lockheed-Martin Corp, 2011). Organizations might expect, then, that concerns about discrimination and lawsuits brought by traditionally-advantaged groups may become more prevalent (and expensive) as diversity initiatives are adopted.

\section{Inclusion Signals}

By adopting diversity initiatives, organizations also intend to signal that their organization is inclusive - that everyone is valued and belongs at the organization. The inclusion signal has important implications for recruitment and for increasing representation of diverse employees, as organizations that signal an inclusive organizational environment are assumed to be more attractive to job seekers from underrepresented groups. This assumption has found some support: one study found that hotel management students (regardless of race) were more interested in working for organizations if they learned the company invested (vs. dis-invested or did not mention investment) in diversity initiatives (Waight \& Madera, 2011). Another showed that job ads with diversity language were more likely to result in a diverse hire than job ads without diversity language (King et al., 2012).

Several studies specifically examined how the presence (vs. absence) of diversity or multicultural messages affects feelings of belonging (or anticipated belonging) among members of underrepresented groups and overrepresented groups. Below, we first discuss reactions of members of underrepresented groups, and then those of overrepresented groups.

Underrepresented groups. Among members of underrepresented groups, evidence is mixed regarding whether diversity initiatives effectively signal a sense of inclusion and anticipated belonging. In a widely cited set of studies, Purdie-Vaughns, Steele, Davies, Diltmann, and Crosby (2008) examined the impact of two factors-multicultural (vs. colorblind) messages about diversity and demographically diverse (vs. homogenous) employee depictionin recruitment brochures on black job applicants' attraction to a company. Among these 
participants, brochures featuring either multicultural messages or photos of diverse employees led to higher attraction to the company and greater anticipated belonging at the company than brochures with neither. In another set of studies, white women and men of color reported higher levels of anticipated belonging in the presence (vs. absence) of diversity initiatives (Chaney et al., 2016). Dover and colleagues (2016), however, found that the presence (vs. absence) of diversity initiatives at a company did not significantly affect the extent to which ethnic and racial minority participants anticipated belonging at the company or reported wanting to work for the company. Similarly, Wilton, Bell, Varhady, and Kaiser (2019) found that Latinx and African Americans experience no greater belonging in an organization that expressed pro-diversity values (vs. control values), yet belonging was increased when organizations actually had a diverse (vs. homogeneous) workforce.

One limitation of the above studies is that participants were asked to imagine how they might fit in at an organization to which they are not actually applying. Such studies provide only limited information about whether diversity initiatives effectively signal inclusion to targeted groups. Dover, Major, and Kaiser (2019) sought to provide a more comprehensive answer to this question. In this study Latino men took part in a stimulated but realistic job interview for company while their cardiovascular threat responses were recorded (see Blascovich, 2008; Dover et al., 2016; Seery, 2013). Prior to the interview, participants viewed a presentation about the company and the job that either did or did not contain information about the company's prodiversity values. If pro-diversity messages effectively signal that minorities are valued and will be included, one might expect minorities interviewing for a pro-diversity company (vs. one that does not mention diversity) to be less threatened, perform better on the job interview, and report more positivity toward the company and anticipated inclusion. Contrary to this expectation, the presence (vs. absence) of diversity messages had no effect on Latino participants' cardiovascular 
reactivity during their interview, nor their coder-rated behavior during the interview. The presence of pro-diversity messages also did not affect how much participants reported that they belonged at the company or how positively they felt toward the company. Rather, participants interviewing for the company with (vs. without) pro-diversity messages reported greater concerns about fairness and greater concerns about being disliked by hiring managers.

This study suggests that diversity initiatives and messages may not make the interview process feel less threatening for Latino men and may ironically create more concerns about being liked and treated fairly. Though this seems to contrast with prior work on the effect of diversity initiatives on anticipated belongingness and fair treatment (Chaney et al., 2016; Purdie-Vaughns et al., 2011), it is not necessarily contradictory. For example, it is possible that other minority groups (e.g., white women, black men and women) are more positively affected by messages about diversity. Alternatively, it is possible that diversity initiatives are important for the attraction of underrepresented candidates, but do not function similarly once candidates are engaged in the actual interview process and thinking about their treatment in a realistic, highstakes simulation.

Inclusion signals for underrepresented groups: Implications. Diversity initiatives can signal inclusion to members of underrepresented groups. Yet some work indicates that they can also prompt greater concerns about fairness and being liked. Thus, it is questionable whether organizations should rely on diversity initiatives as an inclusion signal to underrepresented candidates. In addition, if diversity initiatives lead underrepresented groups to expect belongingness and fair treatment, but do not deliver on this promise-either because they do not make the interview process less threatening or are contrary to the realities of what they actually encounter in the workplace - such initiatives may set up underrepresented groups with unrealistic expectations (Wilton et al., 2019). McKay and Avery (2005) mirror this warning, 
arguing that diversity initiatives can backfire if hopeful minority group members enter workplaces that have promised inclusive and fair workplaces but have not created real organizational change.

Traditionally overrepresented groups. Whereas diversity initiatives are meant to signal inclusion to underrepresented groups, several investigations indicate that diversity initiatives, and indeed the concept of diversity itself, can signal exclusion and threat to members of traditionally advantaged groups. The way diversity is framed can also affect feelings of inclusion and fairness of advantaged groups, which can have important implications for intergroup relations (see Plaut, Thomas, Hurd, \& Romero, 2018). Plaut and colleagues suggest that multicultural values, which emphasize the importance of difference and respect for cultural identity, are perceived by whites to be more exclusionary and threatening than colorblind approaches to diversity, which emphasize the inherent "sameness" of all individuals and de-emphasize difference (Plaut, Garnet, Buffardi, \& Sanchez-Burks, 2011). For example, after being exposed to multicultural (vs. colorblind) messages about diversity, whites (particularly strongly-identified whites) are more likely to endorse social dominance ideologies, more likely to express prejudice toward Asian, Black, and Latino Americans, and less likely to allocate funds to diversity-supportive initiatives (Morrison, Plaut, \& Ybarra, 2010). The association between multicultural ideologies and exclusion seems to be attenuated when multiculturalism is framed as inclusive of all groups, including whites (Plaut et al., 2011; see Stevens, Plaut, \& Sanchez-Burks, 2008). This suggests that feelings of exclusion among advantaged groups are important to consider when looking at the consequences of diversity initiatives.

These investigations did not directly test whether feelings of exclusion translate to whites' anticipated belongingness within organizations. Other work, however, has addressed this question. One study showed that the presence or absence of diversity initiatives had no effect on 
white Americans' anticipated inclusion at a company (Chaney et al., 2016). In another set of studies, white Americans were asked to either imagine or actually engage in an interview with a company that mentioned (vs. did not mention) its diversity initiatives and pro-diversity values (Dover et al., 2016). In these studies as well, white participants did not report any differences in how attractive they found the organization or how included they would feel at the company depending on whether the organization discussed its diversity initiatives and values. However, the presence (vs. absence) of pro-diversity messages led white participants to express greater concerns that their race would put them at a disadvantage at the company. Whites were also more likely to display a cardiovascular profile of threat when interviewing at the company that mentioned (vs. did not mention) its pro-diversity values, indicating that the mere presence of diversity messages may be threatening to whites as they navigate the interview process. Importantly, the negative effects of diversity condition on cardiovascular threat and perceived disadvantage among white men were observed regardless of several relevant individual difference variables, including white racial identification, political ideology, system justification beliefs, prejudice, and motives to respond without prejudice (Dover et al., 2016). This suggests that although whites may not explicitly report anticipating a lack of belonging in organizations with diversity initiatives, such initiatives still signal exclusion and prompt threat, and that these effects are observed even among those we might expect to be supportive of diversity initiatives. Inclusion signals for traditionally advantaged groups: Implications. Given that traditionally advantaged groups hold a disproportionate amount of power within organizations, and the mixed findings regarding the efficacy of diversity initiatives, it is important to consider the consequences of this threat and perceived exclusion. Research is needed to address whether threat and perceptions of exclusion experienced by advantaged groups in the context of diversity initiatives translate to poorer outcomes for members of disadvantaged groups. Past work 
suggests that experiences of group-based identity threat among advantaged groups can lead to enhanced prejudice, support for hierarchy-enhancing policy, discrimination, and aggression (e.g., Bosson, Vandello, Burnaford, Weaver, \& Arzu Wasti, 2009; Craig \& Richeson, 2014; Knowles, Lowery, Unzueta, \& Chow; Wilkins, Wellman, Flavin, \& Manrique, 2017). It is reasonable, then, to expect that the threat and feelings of exclusion resulting from the mere presence of diversity initiatives could negatively influence attitudes and behavior toward members of underrepresented groups.

\section{Competence Signals}

Although not a primary intention of diversity initiatives, a third signal that they send is that members of underrepresented groups need help to succeed within the organization (Leslie, 2018). If members of such groups had the same chance for success as members of more advantaged groups, a diversity initiative would not be needed. The signal that targeted groups need help, however, prompts attributions as to why such groups cannot succeed and can lead to the inference that targeted groups need help to succeed because they lack competence. A number of early experiments demonstrated that women and minorities hired under an affirmative action rationale are subject to a "presumption of incompetence:" they are viewed as less qualified and as less competent than those hired in the absence of such a rationale (Heilman, Block \& Lucas, 1992; Heilman, Block \& Stathatos, 1997). According to attribution theory (Kelley, 1967), the presence of affirmative action (or similar) policies provides an explanation other than merit for the favorable treatment or outcomes of groups that suffer from negative stereotypes (e.g., women and minorities). This attributional ambiguity can lead people to discount the role that merit or competence may have played in their treatment or outcomes (Heilman et al., 1992; Major, Feinstein, \& Crocker, 1994). 
The presence of diversity initiatives may have similar effects on the presumed competence of minorities and women who appear to benefit from such initiatives. Espino-Perez, Major \& Malta (2018), for example, found that Latinx participants rated the qualifications of a highly qualified Latinx job candidate lower if the hiring manager had simply indicated that the candidate would "add diversity" to the organization than if this phrase was omitted. Heilman and Welle (2006) showed that individuals perceived white women or black men who were selected to participate in a workgroup in order to fulfill diversity goals (to ensure demographic representation) as less competent, less likely to have impact, and as less likely to become a leader than white women or black men selected to participate in the work group either due to a "random" rationale (scheduling convenience) or in the absence of any stated rationale. Furthermore, being associated with a diversity goal negatively affected competence ratings of white women and black men, but not white men. These findings are consistent with the idea that negative reactions to those associated with diversity goals are mediated by the discounting process. People infer incompetence only when a demographic category was both a salient and a plausible explanation for why the group member had been selected for participation in the group.

Some recent studies further illustrate the negative impact of diversity initiatives on presumptions of competence. Gündemir, Homan, Usova and Galinsky (2017) found that among white participants, exposure to an organizational mission statement emphasizing diversity led to increased activation of negative stereotypes of minorities, and decreased expectations of the job performance of a black employee compared to exposure to an organizational mission statement expressly signaling that it valued merit.

All of the above experiments examined how the presence of diversity initiatives affects observers' perceptions of employee competence. Almost no research has examined how the presence of diversity initiatives in an organization affects self-perceptions of competence among 
members of underrepresented groups. As research on meta-stereotypes and stereotype threat has amply illustrated, people's beliefs and concerns about how others view them can have a profound impact on their emotions, cognitions and behavior (Steele \& Aronson 1995). Research on stereotype threat demonstrates that individuals are aware of negative stereotypes others hold about their group, and that this awareness reduces cognitive capacity and increases anxiety, both of which impede performance (Schmader, Johns, \& Forbes, 2008; Shapiro \& Neuberg, 2007). To the extent that members of underrepresented groups are aware that diversity initiatives signal they need help and increase stereotypes about how they lack competence, diversity initiatives have the potential to negatively affect their performance. Heilman \& Alcott (2001) found that women led to believe that their male teammate held the view that they had been selected for a role on the basis of gender (vs. on the basis of merit), inferred that he held more negative expectations about their competence to perform the task. In turn, this belief provoked women who were uncertain about their ability on the task to make more timid and risk-averse decisions, and to rate their own self-competence lower.

In one of the few studies to directly address how the presence of diversity initiatives affect self-perceived competence, Dover and colleagues (2019) provided hiring feedback to Latino men after they took part in a simulated hiring interview for a company that did (vs. did not) include pro-diversity messages in their recruitment materials. After completing the interview participants learned either that they had been selected for a position over a white confederate or that the white confederate had been selected for the position. Regardless of whether they had been selected or rejected, Latino participants reported feeling less competent if the organization for which they had interviewed did (vs. did not) have pro-diversity messages. This disturbing finding suggests that the presence of diversity initiatives can make both positive outcomes and negative outcomes attributionally ambiguous for underrepresented groups (Crocker \& Major, 
1989). The presence of pro-diversity messages may exacerbate the negative effects of rejection feedback by increasing negative internal attributions for those outcomes, enhancing self-blame by insinuating that participants could not "make the cut" even when managers are looking to hire members of underrepresented groups (Major et al., 1994). The presence of diversity initiatives may also decrease positive internal attributions and increase external attributions for positive feedback by implying that acceptance was due to group membership rather than personal merit (Heilman et al., 1992; Unzueta, Gutiérrez, \& Ghavami, 2010). Pro-diversity messages, then, may exacerbate attributional ambiguity experienced by ethnic minority applicants who receive positive or negative feedback, reducing their self-perceived competence.

Furthermore, exposure to diversity training and similar initiatives may reduce overt expressions of prejudice against underrepresented groups, leading people to hide or disguise bias in their interactions members of underrepresented groups (Plant \& Devine, 2001). This may increase the extent to which women and minorities experience attributional ambiguity in their interactions with colleagues and managers. Attributional ambiguity can have a variety of negative effects. For example, Latina participants who suspected that a white interaction partner's positive feedback was primarily motivated by her desire to appear unprejudiced had lower self-esteem and were more threatened than those who did not suspect that feedback was externally motivated (Major, Kunstman, Malta, Sawyer, Townsend, \& Mendes, 2016). In another study, black participants who read about a black candidate who was rejected for employment by a white hiring officer showed greater impairment on a test of cognitive performance if the hiring officer offered a subtle, ambiguously prejudiced rationale for the rejection than if he offered a blatantly prejudiced rationale (Salvatore \& Shelton, 2007). Black and Latino participants also exhibited more cognitive interference after interacting with or observing a white partner who displayed subtle racial bias toward an ethnic minority partner than one who displayed blatant 
racial bias (Murphy, Richeson, Shelton, Rheinschmidt, \& Bergsieker, 2013). Cognitive depletion can be costly, impairing performance on intellectual tasks and reducing the ability to detect contemporary prejudice (Carter, Peery, Richeson, \& Murphy, 2015; Schmader \& Johns, 2003).

Competence signals: Implications. Unlike fairness and inclusion signals, competence signals are likely wholly unintended by organizations. Nevertheless, they may create additional barriers for members of underrepresented groups and those that face negative stereotypes in the workplace. In addition, they may create ambiguity for members of underrepresented groups when trying to understand their treatment and outcomes within organizations. For this reason, it may be important to couple discussions of diversity and equity with an emphasis on merit and competence (Gündemir et al., 2017; Walton, Spencer, \& Erman, 2013).

\section{Social Issues \& Policy Implications}

Despite a strong need for effective diversity management within organizations, an accumulating body of research provides little evidence that diversity initiatives as widely practiced create more fair or diverse workplaces. Moreover, as reviewed here, the mere presence of diversity initiatives can send unintended signals that can ironically undermine their primary goals: creating more fair, inclusive, and diverse workplaces. We believe that these unintended signals may be partially responsible for the lackluster effects of diversity initiatives and the continuing problem of employment discrimination despite longstanding legal prohibitions.

Though these conclusions may be discouraging for policymakers and practitioners, there are promising avenues for the improvement of diversity initiatives, and empirical insights can aid practitioners as they (re)design and (re)conceptualize their approach to diversity management. This is not to say that there are unilateral recommendations that will guarantee effective diversity initiatives. However, we can offer several considerations that practitioners and policymakers should weigh and keep in mind as they attempt to create fairer and more inclusive workplaces. 


\section{Framing Diversity Initiatives}

It is important that diversity practitioners effectively frame diversity initiatives so that these efforts maximize benefits and mitigate harm. Because backlash from high status groups presents one of the more salient threats to diversity initiatives, practitioners may accordingly focus their efforts on reducing backlash. One approach to avoiding backlash and increasing the palatability of diversity involves framing diversity broadly so that diversity efforts acknowledge that everyone is diverse and that all types of personal attributes (e.g., personality, communication style) and job characteristics (e.g., job sector within an organization) contribute to diversity.

These broadened definitions of diversity have proliferated within organizations (Edelman et al., 2001). Legal scholars, however, assert that these broadened definitions of diversity are increasingly disconnected from civil rights issues, making diversity offices and initiatives symbolic efforts that do not address inequality experienced by legally protected groups (Edelman, 2016). This distancing of diversity from remediating inequality may explain why high status groups prefer broad construals of diversity, and feel more included and supportive of diversity when it is framed in broad (vs narrow) terms (Jansen, Otten, \& van der Zee, 2015; Plaut et al, 2011). Broadened definitions of diversity, however, can backfire because whites use evidence of high (vs low) organizational diversity on broad attributes (e.g., diversity in functional roles within an organization), to justify perceiving organizations that are low in racially diversity as diverse (Unzueta, Knowles, \& Ho, 2012). Likewise, presenting people with broad (vs. narrow) definitions of diversity causes them to fail to label organizations that are racially homogeneous as having diversity problems (Akinola, 2016). To the extent that broad definitions of diversity inaccurately increase the sense that organizations are racially diverse, this can leave these organizations vulnerable to neglecting the civil rights issues that these initiatives were developed to address. 
Another approach to increasing support for initiatives through framing might be to focus on instrumental rationale of diversity, such as diversity's role in increasing profits or improving problem solving. While there are contexts in which diversity will produce these positive outcomes (Carter \& Phillips, 2017; Galisnky et al., 2015; Sommers, Warp, \& Mahoney, 2008), this is not always or even typically the case (Eagly, 2016; Horwitz \& Horwitz, 2007; Webber \& Donahue, 2001). Critically, predicating the justification for diversity on utilitarian outcomes may also put diversity efforts at risk when instrumental goals are not achieved or there is evidence that diversity does not impact these goals.

In contrast to framing diversity broadly or focusing on instrumental goals, a third approach may be for practitioners to focus on making principled moral arguments that all groups be treated fairly, respectfully, and have access to voice and influence in the decision-making process. This set of principles, collectively referred to as procedural justice (Lind \& Tyler, 1988), is widely valued in all segments of society. Framing diversity as aimed at increasing procedural fairness may make diversity more palatable to those who are advantaged, while also preventing bias from entering the decision-making process. This approach might also avoid diluting the justice goals of diversity initiatives.

\section{Empowering Rather than Constraining Behavior}

Mandatory diversity training has been shown to be less effective than voluntary training (Kalev et al., 2006; Dobbin et al., 2015). Moreover, it has been theorized that diversity initiatives that reduce managerial discretion can lead to defensiveness and backlash because they are perceived as accusing participants of prejudice and constraining free expression of beliefs and ideals (Dobbin et al., 2015; Pendry et al., 2007).

As such, practitioners may want to focus on interventions that seek to empower the autonomy of participants to act in prosocial ways rather than chide them for wrong behavior 
(Deci \& Ryan, 1987). In an important demonstration of effective diversity intervention, Devine and colleagues' prejudice habit-breaking model (Carnes et al., 2015; Devine et al., 2012; 2017; Forscher, Mitamura, Dix, Cox, \& Devine, 2017) capitalizes on participants' internal motivation to treat everyone fairly. Participants actively engage with educational resources and strategies for controlling bias such as practicing counter-stereotypic associations, individuating members of minority groups, and engaging in intergroup contact. In randomized trials in educational contexts, this intervention has been shown to both decrease implicit prejudice and result in higher rates of hiring underrepresented faculty (Carnes et al., 2015; Devine et al., 2012; 2017; Forscher et al., 2017). One reason for this intervention's success may be that participants freely choose to work on their prejudice habit and internalize the importance of the intervention; this may avoid some of the backlash associated with diversity messages and training.

Training that focuses on allyship (i.e., forming supportive associations with members of underrepresented groups, teaching individual employees how to help reduce unfairness in the workplace) may also result in less backlash than other approaches because it allows employees to see themselves as agents of change rather than as targets of bias-reduction initiatives. Learning how to "spot" a bias incident and respond proactively, for example, may both allow participants to question their behavior without feeling called-out and give participants tools for standing up to bias. Allies may also have enhanced credibility with members of their own group when it comes to reducing workplace discrimination. Because allies are viewed as having less vested selfinterest in remedying bias, their claims of bias are viewed as more credible than those of underrepresented groups (Drury \& Kaiser, 2014).

These strategies may work well with individuals who are motivated to reduce prejudice and prevent discrimination, but may not be effective at creating more fair workplaces among those with higher levels of prejudice or who believe that discrimination is not a problem in their 
workplace (Chang et al., 2019). Some critics of diversity training note that attempts to reduce prejudice will only be successful for those with already low levels of prejudice, and that the efforts will likely be ineffective or counterproductive among those high in prejudice (Noon, 2018). As such, organizations may also want to consider strategies that minimize the likelihood that prejudice can directly affect hiring and other personnel decisions.

\section{Discretion-Reducing Hiring and Promotion Policies}

Some policies can be implemented that will reduce bias in hiring and promotion decisions regardless of how diversity is framed or whether managers are working to combat their own prejudice. For example, requiring that job listings be posted widely and in several different outlets helps ensure that qualified workers outside the traditional networks can learn about the opportunity. Similarly, avoiding referral systems in which current employees recommend candidates from their personal networks can help eliminate the tendency for these systems to reproduce the organization's current demographic make-up. Standardizing application and interview processes can also help eliminate disparities that arise from interviewers naturally being more comfortable with members of their own group and unintentionally asking different questions to applicants depending on their group membership (Huffcutt \& Roth, 1998; Levashina, et al,. 2014). Such standardization can also help hiring managers avoid justifying prejudiced decisions by shifting standards and idiosyncratically adjusting the qualifications they consider most important as they move through the hiring process (Dovidio \& Gaertner, 2000).

Organizations can also consider using or creating services that remove demographic information and other identity signifiers from application materials. Though this information cannot always be kept hidden in later stages of the hiring process, it can help avoid bias in the initial screening of applications, an area where bias has been repeatedly demonstrated in labor market studies (Quillian et al., 2017). This blinding strategy may be particularly effective if it is 
combined with a system in which demographic characteristics of the candidate pool are monitored and required to reach pre-determined benchmarks before applicant screening begins. That way, organizations can be more confident that they are not making selections from a pool that is already biased toward certain overrepresented groups.

\section{Fostering Positive Contact}

In the social psychological literature, one of the most well-established strategies for reducing prejudice and fostering positive intergroup relations involves no training and no discussion of prejudice. Intergroup contact theory and research (Allport, 1954; Pettigrew \& Tropp, 2006) maintains that the key to positive intergroup relations is equal-status, cooperative, and interdependent contact with outgroup members. Extending the findings from intergroup contact research to diversity initiatives in organizations may provide fruitful insights for intervention (Paluck, 2006). For example, this literature suggests that effective diversity training would emphasize group commonalities as well as group differences, reduce negative emotions and foster positive emotions such as empathy, and avoid discussing group stereotypes (Paluck, 2006). Organizations might encourage activities in which diverse employees can work together on projects cooperatively and in an equal-status context where friendships might develop. By avoiding the explicit mention of diversity and prejudice, this approach might also avoid the unintended negative consequences of signaling that accompany diversity initiatives and diversity training. For example, a rigorous evaluation of a diversity training program run by the AntiDefamation League that focused on tolerance did not increase participants' personal comfort with members of other groups (Paluck \& Green, 2006; see Paluck, 2006), whereas a field experiment in which an intergroup contact intervention (an Outward Bound camping trip) made no mention of prejudice or social inclusion increased participants' personal comfort with members of other groups (Green \& Wong, 2001). 


\section{Data Collection and Program Evaluation}

Perhaps the most unilateral recommendation we can offer for policymakers and practitioners is to track the efficacy of their diversity initiatives. At the beginning of this review, we suggested that lack of evidence-based practices may be partially responsible for lackluster progress in preventing employment discrimination. Researchers and academics must continue designing and testing diversity interventions and sharing their results with practitioners and policymakers. Practitioners and policymakers themselves, however, can also collect data about how their initiatives affect hiring outcomes, prejudice, perceptions of inclusion, and concerns about discrimination. Too often, the mere presence of a diversity initiative (or the amount of money spent on an initiative) is used as a signal of its efficacy. Practitioners truly committed to the welfare of their workers, however, should be motivated to assess whether their initiatives are achieving their acquired goals, and to course-correct if not.

Measuring the outcomes of diversity initiatives also comes with an important sidebenefit: it requires that organizations specify the goals of their initiatives. As we discussed, organizations try to achieve a lot with their diversity initiatives: they try to create more fair workplaces, facilitate productive and creative workgroups, and signal to stakeholders that they are "doing something" about diversity. It is possible that by attempting to accomplish so many goals, a diversity initiative will become diluted, unfocused, and less effective at achieving the most important goals. Identifying measurable goals — greater feelings of inclusion, increased diversity of the applicant pool, greater knowledge about how to detect and report discrimination, decreased concerns about discrimination, or decreased experiences with discrimination — will not only lead to more effective interventions but also remind organizational leaders what their diversity-related goals are. Social science can provide some importance insights into what should and should not work when implementing diversity initiatives, as well as the unintended 
consequences to keep in mind. However, because each organization has its own culture and norms, it may take some humility, openness to feedback, and critical self-assessment to reach the goal of inclusive and fair workplaces.

\section{Conclusion}

Organizations around the world have been tasked with the important goal of creating more fair, diverse, and inclusive workplaces. With such high stakes, researchers and practitioners must work together to design, implement, and test interventions that maximize the benefits and minimize the costs of diversity initiatives. By considering the signaling consequences of diversity initiatives, we hope practitioners can come closer to achieving their laudable goals. 


\section{References}

Akinola, M. (2016). Diversity isn't what it Used to Be: The Consequences of Broad Diversity Definitions. Presented at the 2016 Gender and Work Symposium, Boston, MA (22 May, 2016).

Allport, G. (1954). The nature of prejudice. Reading, MA: Addison-Wesley.

Avery, D.R., McKay, P.F., Wilson, D.C., \& Tonidandel, S. (2007). Unequal attendance: The relationships between race, organizational diversity cues, and absenteeism. Personnel Psychology, 60(4), 875-902. doi: 10.1111/j.1744-6570.2007.00094.x

Baert, S. (2018). Hiring discrimination: an overview of (almost) all correspondence experiments since 2005. In S.M. Gaddis (Ed.), Audit studies: Behind the scenes with theory, method, and nuance (pp. 63-77). Cham, Switzerland: Springer.

Bell, M.P., Connerley, M.L., \& Cocchiara, F.K. (2009). The case for mandatory diversity education. Academy of Management Learning \& Education, 8(4), 597-609. doi: 10.5465/amle.8.4.zqr597

Bell, M.P., \& Kravitz, D.A. (2008). What do we know and need to learn about diversity education and training? Academy of Management Learning \& Education, 7(3), 301-308. 10.5465/amle.2008.34251669

Berrey, E. (2015). The enigma of diversity: The language of race and the limits of racial justice. Chicago, IL: University of Chicago Press.

Bezrukova, K., Jehn, K A., \& Spell, C.S. (2012). Reviewing diversity training: Where we have been and where we should go. Academy of Management Learning \& Education, 11(2), 207-227. doi: 10.5465/amle.2008.0090 
Bezrukova, K., Spell, C.S., Perry, J.L., \& Jehn, K.A. (2016). A meta-analytical integration of over 40 years of research on diversity training evaluation. Psychological Bulletin, 142(11), 1227. doi: 10.1037/bul0000067

Bi, S. W. (2016). Race-based reverse employment discrimination claims: A combination of factors to the prima facie case for caucasian plaintiffs. Cardozo Law Review De-Novo, 2016, 40-76.

Blascovich, J. (2008). Challenge, threat, and health. In J. Y. Shah \& W. L. Gardner (Eds.), Handbook of motivation science (pp. 481-493). New York, NY, US: The Guilford Press.

Bosson, J.K., Vandello, J.A., Burnaford, R.M., Weaver, J.R., \& Arzu Wasti, S. (2009). Precarious manhood and displays of physical aggression. Personality and Social Psychology Bulletin, 35(5), 623-634. doi: 10.1177/0146167208331161

Brady, L.M., Kaiser, C.R., Major, B., \& Kirby, T.A. (2015). It's fair for us: Diversity structures cause women to legitimize discrimination. Journal of Experimental Social Psychology, 57, 100-110. doi: 10.1016/j.jesp.2014.11.010

Carnes, M., Devine, P. G., Manwell, L. B., Byars-Winston, A., Fine, E., Ford, C. E., ... \& Palta, M. (2015). Effect of an intervention to break the gender bias habit for faculty at one institution: a cluster randomized, controlled trial. Academic medicine: journal of the Association of American Medical Colleges, 90(2), 221.

Carter, A.B., \& Phillips, K.W. (2017). The double-edged sword of diversity: Toward a dual pathway model. Social and Personality Psychology Compass, 11(5), e12313. doi: $10.1111 / \mathrm{spc} 3.12313$

Carter, E.R., Peery, D., Richeson, J.A., \& Murphy, M.C. (2015). Does cognitive depletion shape bias detection for minority group members? Social Cognition, 33(3), 241-254. doi: $10.1521 /$ soco.2015.33.3.241 
Chaney, K.E., Sanchez, D.T., \& Remedios, J.D. (2016). Organizational identity safety cue transfers. Personality and Social Psychology Bulletin, 42(11), 1564-1576. doi: $10.1177 / 0146167216665096$

Chang, E.H., Milkman, K.L., Gromet, D.M., Rebele, R.W., Massey, C., Duckworth, A L., \& Grant, A.M. (2019). The mixed effects of online diversity training. Proceedings of the National Academy of Sciences, 116(16), 7778-7783. doi: 10.1073/pnas.1816076116

Chen, C. (2018, May 14). Nike Aims to Transform Troubled Workplace With New Diversity Initiatives. Business of Fashion. Retrieved from <https://www.businessoffashion.com/articles/news-analysis/nike-looks-to-transformtroubled-workplace-culture-with-new-diversity-initiatives>

Cox, T.H., \& Blake, S. (1991). Managing cultural diversity: Implications for organizational competitiveness. Academy of Management Perspectives, 5(3), 45-56. doi: 10.5465/ame.1991.4274465

Craig, M. A., \& Richeson, J. A. (2014). More diverse yet less tolerant? How the increasingly diverse racial landscape affects white Americans' racial attitudes. Personality and Social Psychology Bulletin, 40(6), 750-761.

Crocker, J., \& Major, B. (1989). Social stigma and self-esteem: The self-protective properties of stigma. Psychological Review, 96(4), 608-630.

Deci, E.L., \& Ryan, R.M. (1987). The support of autonomy and the control of behavior. Journal of Personality and Social Psychology, 53(6), 1024-1037. doi: 10.1037/00223514.53.6.1024

Devine, P. G., Forscher, P. S., Austin, A. J., \& Cox, W. T. (2012). Long-term reduction in implicit race bias: A prejudice habit-breaking intervention. Journal of Experimental Social Psychology, 48(6), 1267-1278. 
Devine, P. G., Forscher, P. S., Cox, W. T., Kaatz, A., Sheridan, J., \& Carnes, M. (2017). A gender bias habit-breaking intervention led to increased hiring of female faculty in STEMM departments. Journal of Experimental Social Psychology, 73, 211-215.

Dobbin, F., \& Kalev, A. (2017). Are diversity programs merely ceremonial? Evidence-free institutionalization. In R. Greenwood, C. Oliver, T.B. Lawrence \& R.E. Meyer (Eds.), The SAGE Handbook of Organizational Institutionalism (pp. 808-828). London, UK: Sage Publishing.

Dobbin, F., Schrage, D., \& Kalev, A. (2015). Rage against the iron cage: The varied effects of bureaucratic personnel reforms on diversity. American Sociological Review, 80(5), 10141044. doi: $10.1177 / 0003122415596416$

Dover, T.L., Major, B., \& Kaiser, C.R. (2014). Diversity initiatives, status, and system-justifying beliefs: When and how diversity efforts de-legitimize discrimination claims. Group Processes \& Intergroup Relations, 17(4), 485-493. doi: 10.1177/1368430213502560

Dover, T.L., Major, B., \& Kaiser, C.R. (2016). Members of high-status groups are threatened by pro-diversity organizational messages. Journal of Experimental Social Psychology, 62, 58-67. doi: 10.1016/j.jesp.2015.10.006

Dover, T.L., Major, B. and Kaiser, C.R. (2019). Cardiovascular, behavioral, and psychological responses to organizational pro-diversity messages among Latino men. Manuscript under review.

Dovidio, J.F., \& Gaertner, S.L. (2000). Aversive racism and selection decisions: 1989 and 1999. Psychological Science, 11(4), 315-319. doi: 10.1111/1467-9280.00262

Dovidio, J.F., \& Gaertner, S.L. (2004). Aversive racism. Advances in Experimental Social Psychology, 36, 4-56. doi: 10.1016/S0065-2601(04)36001-6 
Drury, B.J., \& Kaiser, C.R. (2014). Allies against sexism: The role of men in confronting sexism. Journal of Social Issues, 70(4), 637-652. doi: 10.1111/josi.12083

Dweck, C.S. (2006). Mindset: The new psychology of success. New York, NY: Random House. Eagly, A.H. (2016). When passionate advocates meet research on diversity, does the honest broker stand a chance? Journal of Social Issues, 72(1), 199-222. doi: 10.1111/josi.12163

Edelman, L.B. (2016). Working law: Courts, corporations, and symbolic civil rights. Chicago, IL: University of Chicago Press.

Edelman, L.B., Fuller, S.R., \& Mara-Drita, I. (2001). Diversity rhetoric and the managerialization of law. American Journal of Sociology, 106(6), 1589-1641. doi: $10.1086 / 321303$

Edelman, L.B., Krieger, L.H., Eliason, S.R., Albiston, C.R., \& Mellema, V. (2011). When organizations rule: Judicial deference to institutionalized employment structures. American Journal of Sociology, 117(3), 888-954. doi: 10.1086/661984

Espino-Pérez, K., Major, B., \& Malta, B. (2018). Was it race or merit?: The cognitive costs of observing the attributionally ambiguous hiring of a racial minority. Cultural Diversity and Ethnic Minority Psychology, 24(2), 272-276. doi: 10.1037/cdp0000153

Evans, W.D., 2004. Reverse discrimination claims: growing like kudzu. Maryland Bar Journal, $37(1), 48-51$.

Fazio, R.H., \& Olson, M.A. (2003). Implicit measures in social cognition research: Their meaning and use. Annual Review of Psychology, 54(1), 297-327.

Feloni, R. (2016, Jan 16). Here's everything Facebook is doing this year to address its 'pathetic' diversity numbers. Business Insider. Retrieved from <https://www.businessinsider.com/facebooks-2016-strategy-for-improving-diversity2016-1> 
Fisher v. University of Texas, 570 U.S. _ (2013).

Fisher v. University of Texas, 579 U.S. _ (2016).

Forscher, P.S., Lai, C.K., Axt, J., Ebersole, C.R., Herman, M., Devine, P.G., \& Nosek, B.A. (2016). A meta-analysis of change in implicit bias. Retrieved from 〈psyarxiv.com/dv8tu> Furlong v. The Chief Constable of Cheshire Police (2019). Case No. 2405577/18.

Galinsky, A.D., Todd, A.R., Homan, A.C., Phillips, K.W., Apfelbaum, E.P., Sasaki, S.J., ... \& Maddux, W.W. (2015). Maximizing the gains and minimizing the pains of diversity: A policy perspective. Perspectives on Psychological Science, 10(6), 742-748. doi: $10.1177 / 1745691615598513$

Glick, P., \& Fiske, S.T. (1996). The ambivalent sexism inventory: Differentiating hostile and benevolent sexism. Journal of Personality and Social Psychology, 70(3), 491-512.

Green, D.P., \& Wong, J.S. (2009). Tolerance and the contact hypothesis: A field experiment. In E. Borgida, C.M. Federico, \& J.L. Sullivan (Eds.), The political psychology of democratic citizenship (pp. 228-246). New York: Oxford University Press.

Gündemir, S., Homan, A. C., Usova, A., \& Galinsky, A.D. (2017). Multicultural meritocracy: The synergistic benefits of valuing diversity and merit. Journal of Experimental Social Psychology, 73, 34-41. doi: 10.1016/j.jesp.2017.06.002

Guynn, J. (2015, May 5). Exclusive: Google raising stakes on diversity. USA Today. Retrieved from <https://www.usatoday.com/story/tech/2015/05/05/google-raises-stakes-diversityspending/26868359/>

Heilman, M.E., \& Alcott, V.B. (2001). What I think you think of me: Women's reactions to being viewed as beneficiaries of preferential selection. Journal of Applied Psychology, 86(4), 574-582. doi: 10.1037/0021-9010.86.4.574 
Heilman, M.E., Block, C.J., \& Lucas, J.A. (1992). Presumed incompetent? Stigmatization and affirmative action efforts. Journal of Applied Psychology, 77(4), 536-544. doi: 10.1037/

Heilman, M.E., Block, C.J., \& Stathatos, P. (1997). The affirmative action stigma of incompetence: Effects of performance information ambiguity. The Academy of Management Journal, 40, 603-625. doi:10.2307/257055

Heilman, M.E., \& Welle, B. (2006). Disadvantaged by Diversity? The Effects of Diversity Goals on Competence Perceptions 1. Journal of Applied Social Psychology, 36(5), 1291-1319. doi: 10.1111/j.0021-9029.2006.00043.x

Herzog, K. (2018, Apr 17). Is Starbucks Implementing Flawed Science in Their Anti-Bias Training? The Stranger. Retrieved from <https://www.thestranger.com/slog/2018/ 04/17/26052277/is-starbucks-implementing-flawed-science-in-their-anti-bias-training>

Hicks-Clarke, D., \& Iles, P. (2000). Climate for diversity and its effects on career and organisational attitudes and perceptions. Personnel Review, 29(3), 324-345. doi:

$10.1108 / 00483480010324689$

Hofmann, W., Gawronski, B., Gschwendner, T., Le, H., \& Schmitt, M. (2005). A meta-analysis on the correlation between the Implicit Association Test and explicit self-report measures. Personality and Social Psychology Bulletin, 31(10), 1369-1385.

Horwitz, S.K., \& Horwitz, I.B. (2007). The effects of team diversity on team outcomes: A metaanalytic review of team demography. Journal of Management, 33(6), 987-1015. doi: $10.1177 / 0149206307308587$

Howell, J.L., \& Ratliff, K.A. (2017). Not your average bigot: The better-than-average effect and defensive responding to Implicit Association Test feedback. British Journal of Social Psychology, 56(1), 125-145. doi: 10.1111/bjso.12168 
Howell, J.L., Redford, L., Pogge, G., \& Ratliff, K.A. (2017). Defensive responding to IAT feedback. Social Cognition, 35(5), 520-562. doi: 10.1521/soco.2017.35.5.520

Hussey, I., \& De Houwer, J. (2018). Completing a Race IAT increases implicit racial bias. Retrieved from <https://psyarxiv.com/vxsj7/>

Huffcutt, A.I., \& Roth, P.L. (1998). Racial group differences in employment interview evaluations. Journal of Applied Psychology, 83(2), 179. doi: 10.1037/0021-9010.83.2.179

Jansen, W. S., Otten, S., \& van der Zee, K.I. (2015). Being part of diversity: The effects of an all-inclusive multicultural diversity approach on majority members' perceived inclusion and support for organizational diversity efforts. Group Processes \& Intergroup Relations, 18(6), 817-832. doi: 10.1177/1368430214566892

Johansson, A. (19 Dec 2017). Why Millennials Are Demanding Even More Diversity In Tech. Forbes. Retrieved from <https://www.forbes.com/sites/annajohansson/2017/12/19/whymillennials-are-demanding-even-more-diversity-in-tech/\#f8b7833386b3>

Kaiser, C.R., Dover, T.D., Small, P., Xia, G., Brady, L.M., \& Major, B. (2019). Diversity Initiatives and White Americans' Perceptions of Racial Victimhood. Manuscript under review.

Kaiser, C.R., Major, B., Jurcevic, I., Dover, T.L., Brady, L.M., \& Shapiro, J.R. (2013). Presumed fair: Ironic effects of organizational diversity structures. Journal of Personality and Social Psychology, 104(3), 504-519. 10.1037/a0030838

Kaiser, C.R., \& Quintanilla, V.D. (2014). Access to Counsel: Psychological Science Can Improve the Promise of Civil Rights Enforcement. Policy Insights from the Behavioral and Brain Sciences, 1(1), 95-102. doi: 10.1177/2372732214548429 
Kalev, A., Dobbin, F., \& Kelly, E. (2006). Best practices or best guesses? Assessing the efficacy of corporate affirmative action and diversity policies. American Sociological Review, 71(4), 589-617. doi: 10.1177/000312240607100404

Kelley, H.H. (1967). Attribution theory in social psychology. In D. Levine (Ed.), Nebraska symposium on motivation (Vol. 15, pp. 192-238). Lincoln: University of Nebraska Press

Kellough, J.E., \& Naff, K.C. (2004). Responding to a wake-up call: An examination of federal agency diversity management programs. Administration \& Society, 36(1), 62-90. doi: $10.1177 / 0095399703257269$

Kirby, T.A., Kaiser, C.R., \& Major, B. (2015). Insidious procedures: Diversity awards legitimize unfair organizational practices. Social Justice Research, 28(2), 169-186. doi: $10.1007 / \mathrm{s} 11211-015-0240-\mathrm{Z}$

King, B.G. \& McDonnell, M. (2015). Good firms, good targets: The relationship among corporate social responsibility, reputation, and activist targeting. In K. Tsutsui \& A. Lim (Eds.), Corporate Social Responsibility in a Globalizing World (pp. 430-454). New York: Cambridge University Press.

King, E.B., Dawson, J.F., Kravitz, D.A., \& Gulick, L.M. (2012). A multilevel study of the relationships between diversity training, ethnic discrimination and satisfaction in organizations. Journal of Organizational Behavior, 33(1), 5-20. doi: 10.1002/job.728

Knowles, E.D., Lowery, B.S., Chow, R.M., \& Unzueta, M.M. (2014). Deny, distance, or dismantle? How white Americans manage a privileged identity. Perspectives on Psychological Science, 9(6), 594-609. doi: 10.1177/1745691614554658

Kulik, C.T., \& Roberson, L. (2008a). Common goals and golden opportunities: Evaluations of diversity education in academic and organizational settings. Academy of Management Learning \& Education, 7(3), 309-331. doi: 10.5465/amle.2008.34251670 
Kulik, C.T., \& Roberson, L. (2008b). Diversity initiative effectiveness: What organizations can (and cannot) expect from diversity recruitment, diversity training, and formal mentoring programs. In A.P. Brief (Ed.), Diversity at work (pp. 265-317). New York: Cambridge University Press.

Lai, C.K., Marini, M., Lehr, S.A., Cerruti, C., Shin, J.E. L., Joy-Gaba, J.A., ... \& Frazier, R.S. (2014). Reducing implicit racial preferences: I. A comparative investigation of 17 interventions. Journal of Experimental Psychology: General, 143(4), 1765.

Lai, C.K., Skinner, A.L., Cooley, E., Murrar, S., Brauer, M., Devos, T., . . Nosek, B.A. (2016). Reducing implicit racial preferences: II. Intervention effectiveness across time. Journal of Experimental Psychology: General, 145(8), 1001-1016. doi: 10.1037/xge0000179

Leslie, L.M. (2018). Diversity initiative effectiveness: A typological theory of unintended consequences. Academy of Management Review. Advance online publication. doi:10.5465/amr.2017.0087

Levashina, J., Hartwell, C.J., Morgeson, F.P., \& Campion, M.A. (2014). The structured employment interview: Narrative and quantitative review of the research literature. Personnel Psychology, 67(1), 241-293. doi: 10.1111/peps.12052

Lind, E.A., \& Tyler, T.R. (1988). The social psychology of procedural justice. New York: Plenum Press.

Link, B.G. \& Phelan, J.C. (2001). Conceptualizing stigma. Annual Review of Sociology, 27, 363385. doi: 10.1146/annurev.soc.27.1.363

Major, B., Feinstein, J., \& Crocker, J. (1994). Attributional ambiguity of affirmative action. Basic and Applied Social Psychology, 15(1-2), 113-141. doi: $10.1080 / 01973533.1994 .9646075$ 
Major, B., Kunstman, J.W., Malta, B.D., Sawyer, P.J., Townsend, S.S., \& Mendes, W.B. (2016). Suspicion of motives predicts minorities' responses to positive feedback in interracial interactions. Journal of Experimental Social Psychology, 62, 75-88. doi:

10.1016/j.jesp.2015.10.007

Marques, J.F. (2010). Colorful window dressing: A critical review on workplace diversity in three major American corporations. Human Resource Development Quarterly, 21(4), 435-446. doi: 10.1002/hrdq.20045

McFarlin, D.B., \& Sweeney, P.D. (1992). Distributive and procedural justice as predictors of satisfaction with personal and organizational outcomes. Academy of management Journal, 35(3), 626-637. doi: 10.5465/256489

McGuire, G.M. (2002). Gender, race, and the shadow structure: A study of informal networks and inequality in a work organization. Gender \& Society, 16(3), 303-322. doi: $10.1177 / 0891243202016003003$

McKay, P.F., \& Avery, D.R. (2005). Warning! Diversity recruitment could backfire. Journal of Management Inquiry, 14(4), 330-336. doi: 10.1177/1056492605280239

McKay, P.F., Avery, D.R., Tonidandel, S., Morris, M. A., Hernandez, M., \& Hebl, M. R. (2007). Racial differences in employee retention: Are diversity climate perceptions the key? Personnel psychology, 60(1), 35-62. doi: 10.1111/j.1744-6570.2007.00064.x

Moorman, R.H., Niehoff, B.P., \& Organ, D.W. (1993). Treating employees fairly and organizational citizenship behavior: Sorting the effects of job satisfaction, organizational commitment, and procedural justice. Employee Responsibilities and Rights Journal, 6(3), 209-225. doi: 10.1007/BF01419445

Morrison, K.R., Plaut, V.C., \& Ybarra, O. (2010). Predicting whether multiculturalism positively or negatively influences White Americans' intergroup attitudes: The role of ethnic 
identification. Personality and Social Psychology Bulletin, 36(12), 1648-1661. doi: $10.1177 / 0146167210386118$

Murphy, M.C., Richeson, J.A., Shelton, J.N., Rheinschmidt, M. L., \& Bergsieker, H. B. (2013). Cognitive costs of contemporary prejudice. Group Processes \& Intergroup Relations, 16(5), 560-571. doi: 10.1177/1368430212468170

Naff, K.C., \& Kellough, J.E. (2003). Ensuring employment equity: Are federal diversity programs making a difference? International Journal of Public Administration, 26(12), 1307-1336. doi: 10.1081/PAD-120024399

Noon, M. (2018). Pointless diversity training: unconscious bias, new racism and agency. Work, Employment and Society, 32(1), 198-209. doi: 10.1177/0950017017719841

Paluck, E.L. (2006). Diversity training and intergroup contact: A call to action research. Journal of Social Issues, 62(3), 577-595. doi: 10.1111/j.1540-4560.2006.00474.x

Paluck, E.L., \& Green, D.P. (2006). Anti-bias education and peer influence as two strategies to reduce prejudice: An impact evaluation of the anti-defamation league peer training program. Unpublished Manuscript.

Pendry, L.F., Driscoll, D.M., \& Field, S.C. (2007). Diversity training: Putting theory into practice. Journal of Occupational and Organizational Psychology, 80(1), 27-50. doi: $10.1348 / 096317906 X 118397$

Pettigrew, T.F., \& Tropp, L.R. (2006). A meta-analytic test of intergroup contact theory. Journal of Personality and Social Psychology, 90, 751-783. doi: 10.1037/0022-3514.90.5.751

Plant, E.A., \& Devine, P.G. (2001). Responses to other-imposed pro-Black pressure: Acceptance or backlash? Journal of Experimental Social Psychology, 37(6), 486-501. doi: 10.1006/jesp.2001.1478 
Plaut, V.C., Garnett, F.G., Buffardi, L.E., \& Sanchez-Burks, J. (2011). "What about me?” Perceptions of exclusion and Whites' reactions to multiculturalism. Journal of Personality and Social Psychology, 101(2), 337-353. doi: 10.1037/a0022832

Plaut, V.C., Thomas, K.M., \& Goren, M.J. (2009). Is Multiculturalism or Color Blindness Better for Minorities? Psychological Science, 20(4), 444-446. doi: 10.1111/j.14679280.2009.02318.x

Plaut, V.C., Thomas, K.M., Hurd, K., \& Romano, C.A. (2018). Do Color Blindness and Multiculturalism Remedy or Foster Discrimination and Racism? Current Directions in Psychological Science, 27(3), 200-206. doi: 10.1177/0963721418766068

Purdie-Vaughns, V., Steele, C.M., Davies, P.G., Ditlmann, R., \& Crosby, J.R. (2008). Social identity contingencies: How diversity cues signal threat or safety for African Americans in mainstream institutions. Journal of Personality and Social Psychology, 94(4), 615-630. doi: 10.1037/0022-3514.94.4.615

Quillian, L., Pager, D., Hexel, O., \& Midtbøen, A.H. (2017). Meta-analysis of field experiments shows no change in racial discrimination in hiring over time. Proceedings of the National Academy of Sciences, 114(41), 10870-10875. doi: 10.1073/pnas.1706255114

Regents of University of California vs. Bakke, 438 U.S. 265 (1978).

Roberson, L., Kulik, C.T., \& Tan, R.Y. (2012). Effective Diversity Training. In Q.M. Roberson (Ed.), The Oxford handbook of diversity and work (pp. 341-365). New York: Oxford University Press.

Salvatore, J., \& Shelton, J.N. (2007). Cognitive costs of exposure to racial prejudice. Psychological Science, 18(9), 810-815. doi: 10.1111/j.1467-9280.2007.01984.x 
Scheiber, N., \& Abrams, R. (2018, Apr 18). Can Training Eliminate Biases? Starbucks Will Test the Thesis. New York Times. Retrieved from <https://www.nytimes.com/2018/04/18/business/starbucks-racial-bias-training.html>

Schmader, T., \& Johns, M. (2003). Converging evidence that stereotype threat reduces working memory capacity. Journal of Personality and Social Psychology, 85(3), 440-452. doi: 10.1037/0022-3514.85.3.440

Schmader, T., Johns, M., \& Forbes, C. (2008). An integrated process model of stereotype threat effects on performance. Psychological Review, 115(2), 336-356. doi: 10.1037/0033295X.115.2.336

Seery, M. D. (2013). The biopsychosocial model of challenge and threat: Using the heart to measure the mind. Social and Personality Psychology Compass, 7(9), 637-653. doi: $10.1111 / \mathrm{spc} 3.12052$

Shapiro, J.R., \& Neuberg, S.L. (2007). From stereotype threat to stereotype threats: Implications of a multi-threat framework for causes, moderators, mediators, consequences, and interventions. Personality and Social Psychology Review, 11(2), 107-130. doi: $10.1177 / 1088868306294790$

Smith v. Lockheed-Martin Corp., 644 F.3d 1321 (11th Cir., 2011)

Smith, D.G., Turner, C.S., Osei-Kofi, N., \& Richards, S. (2004). Interrupting the usual: Successful strategies for hiring diverse faculty. The Journal of Higher Education, 75(2), 133-160. doi: 10.1080/00221546.2004.11778900

Sommers, S.R., Warp, L.S., \& Mahoney, C.C. (2008). Cognitive effects of racial diversity: White individuals' information processing in heterogeneous groups. Journal of Experimental Social Psychology, 44(4), 1129-1136. doi: 10.1016/j.jesp.2008.01.003 
Staley, O. (10 Oct 2017). Out of corporate America's diversity failures, a new industry is emerging. Quartz. Retrieved from <https://qz.com/work/1092540/techs-diversityfailures-are-a-massive-business-opportunity-for-the-minority-recruitment-industry/>

Steele, C.M., \& Aronson, J. (1995). Stereotype threat and the intellectual test performance of African Americans. Journal of Personality and Social Psychology, 69(5), 797-811. doi: $10.1037 / 0022-3514.69 .5 .797$

Stevens, F.G., Plaut, V.C., \& Sanchez-Burks, J. (2008). Unlocking the benefits of diversity: Allinclusive multiculturalism and positive organizational change. The Journal of Applied Behavioral Science, 44(1), 116-133. doi: 10.1177/0021886308314460

Unzueta, M.M., Gutiérrez, A.S., \& Ghavami, N. (2010). How believing in affirmative action quotas affects White women's self-image. Journal of Experimental Social Psychology, 46(1), 120-126. doi: 10.1016/j.jesp.2009.08.017

Unzueta, M.M., Knowles, E.D., \& Ho, G. C. (2012). Diversity is what you want it to be: How social-dominance motives affect construals of diversity. Psychological Science, 23(3), 303-309. doi: 10.1177/0956797611426727

Waight, J., \& Madera, J.M. (2011). Diversity training: examining minority employees' organizational attitudes. Worldwide Hospitality and Tourism Themes, 3(4), 365-376. doi: $10.1108 / 17554211111162471$

Wal-Mart v. Dukes, 564 U.S. 338 (2011).

Walton, G.M., Spencer, S.J., \& Erman, S. (2013). Affirmative meritocracy. Social Issues and Policy Review, 7(1), 1-35. doi: 10.1111/j.1751-2409.2012.01041.x

Webber, S.S., \& Donahue, L.M. (2001). Impact of highly and less job-related diversity on work group cohesion and performance: A meta-analysis. Journal of Management, 27(2), 141162. doi: $10.1177 / 014920630102700202$ 
Welle, B., \& Heilman, M.E. (2007). Formal and informal discrimination against women at work. In S.W. Gilliland, D.D. Steiner \& D.P. Skarlicki (Eds), Research in social issues in management: Managing social and ethical issues in organizations (pp. 229-252). Greenwich, CT: Information Age Publishing, Inc.

Wilkins, C.L., Wellman, J.D., Flavin, E.L., \& Manrique, J.A. (2017). When Men Perceive Antimale Bias: Status-Legitimizing Beliefs Increase Discrimination Against Women. Psychology of Men \& Masculinity, 19, 282-290. doi: 10.1037/men0000097

Wilton, Bell, Varhady, \& Kaiser, C.R. (2019). Show don’t tell: Diversity dishonesty harms racial/ethnic minorities at work. Manuscript under review. 